\title{
A PRIESTLY VIEW OF BIBLE ARITHMETIC: Deity's Regulative Aesthetic Activity Within Davidic Musicology
}

Ernest G. McClain

Brooklyn College, ernestmcc@verizon.net

Follow this and additional works at: https://fordham.bepress.com/phil_research

Part of the Biblical Studies Commons, Esthetics Commons, History of Religions of Western Origin Commons, Musicology Commons, and the Other Music Commons

\section{Recommended Citation}

McClain, Ernest G., "A PRIESTLY VIEW OF BIBLE ARITHMETIC: Deity's Regulative Aesthetic Activity Within Davidic Musicology" (2002). Research Resources. 23.

https://fordham.bepress.com/phil_research/23 
It becomes easy to understand, then, that just as the way up for human knowing must pass through the senses to arrive at intellectually understood truth, so on the way down from its own intelligent possession of some truth or inherited wisdom to expressing and sharing this with another human being we should naturally seek to reclothe our abstracted wisdom in some vivid imagery that will resonate more powerfully and connaturally within the whole being, soul and body, of the other person. To do this one must call upon the creative imagination, since neither the communicator nor the receiver is having a present sensory experience from which to abstract it. The wisdom story is a wonderfully apt way of expressing and passing down my own or my culture's inherited wisdom, reclothed by the creative imagination in the language of an engaging story, to a receiver who is also a body-soul knower. And what is essential to grasp here is that this product of the creative imagination, the story, is taken in as a whole all at once - not first the images, then the meaning abstracted from it - but the idea shining in and through the concrete image-complex of the story itself, i.e., an idea not abstracted from, but incarnate in, an image. We in the West often like to reflect on the story afterwards and formulate abstractly the universal truth embedded therein. But in many oral cultures, apparently, such as the Native American, they do not like to do that. They say the meaning is in the story, and should not be separated out, for life itself is a story!

Another important evidence that reveals the role of the intellectual soul at work within the creative imagination is the freedom involved in the creative combination or construction of new images, such as mermaids, giants, elves, other worlds entirely (as in science fiction). Animals seem to have a limited creativity of imagination in making up new ways to solve present practical problems - an Australian friend of mine insists his sheep dog constantly amazes him by its creativity in solving problems of herding sheep. But this undeniable imaginative creativity is always limited to solving present practical problems. Our human creativity of imagination seems to have an unlimited range of creation of new images for the sheer joy or thrill of it, independently of any immediate sense-presented practical problem. But such wide-ranging freedom, transcending any immediate present of space and time, is a distinctive mark of the spiritual will, linked directly with its sister faculty of the soul, intelligence itself.

In sum, transcendence over space, time, and material particularity of context, plus unlimited freedom of creativity in the combination or construction of images, are thus the hallmark of the human creative imagination, and a privileged expression of the intrinsic unity of soul and body in a product that manifests the integrated collaboration of both levels of our human nature at once in a unique human artifact.

\section{NOTES}

A survey of the history of philosophy reveals that the question of the nature and value of the creative imagination in human beings turns out to be a sign of contradiction among philosophers, evoking strongly opposed opinions on several points; it thus serves as a touchstone of the thinker's more fundamental position on the nature of the union between body and soul, or what it means to be authentically human. I have been much helped in this latter exploration by the recently published and extremely valuable Summa on the imagination by Eva Brann, The World of Imagination (Lanham: Rowman \& Littlefield, 1991)

ERNEST G. MCCLAIN

\section{A PRIESTLY VIEW OF BIBLE ARITHMETIC:}

Deity's Regulative Aesthetic Activity Within Davidic Musicology

\section{INTRODUCTION}

In "Music as Basic Metaphor and Deep Structure in Plato and in Ancient Cultures," Patrick Heelan modified the concepts of Boolean algebra to accord with Plato's musicalized political theory in the fourth century $\mathrm{BC} .^{1}$ The result is a non-distributive lattice of partially ordered sets displayed in Figure 1.

$T_{1}$

(Infinitely variable tuning - including equal temperament

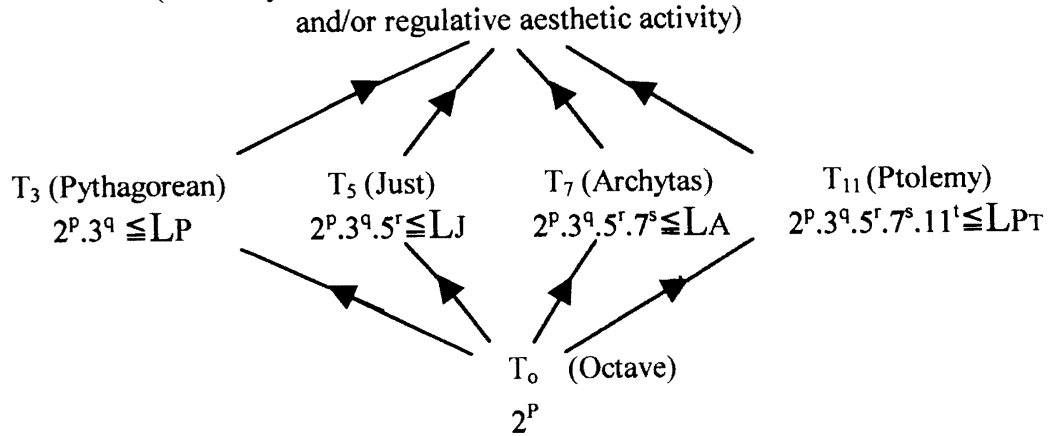

Figure 1. Lattice of Musical Tunings

Heelan's algebra is illustrated here with examples from the Bible suggesting that much authorial narrative is harmonical allegory. His carefully defined symbols embrace a mythologized early Mesopotamian "net of the Gods" in which this material was refined in the matrix arithmetic of the cuneiform record before the emergence of Judaism in the second millennium BC. Hebrew development constitutes a Davidic musicology inspiring prophesy, ritual, narrative, and numerology in both Old and New Testaments.

The dramatic power of Heelan's formal lattice to synthesize an ancient mathematical allegory extending from the first page of Genesis to the last page of Revelation requires studying his symbols in the metaphors of Bible authors. Only Plato

B. E. Babich (ed.), Hermeneutic Philosophy of Science, Van Gogh's Eyes, and God:

Essays in Honor of Patrick A. Heelan, S.J., 429-443.

(C) 2002 Kluwer Academic Publishers. Printed in the Netherlands. 
carefully explains the forgotten matrix arithmetic, and he has been widely ignored except by Philo of Alexandria who has been mistrusted. ${ }^{2}$ Once the reader adopts an appropriate mind set, bible authors prove to explain their models with remarkable clarity. Tuning theory is made possible by the ear's ability to discriminate consonances with considerable accuracy. Only ratio matters. Fractions are avoided by the use of least common multiples. Numerosity is governed by the principle of smallest integers in every context; the Chosen are "the fewest of all peoples." 3 And because pitch perception as rising or falling is quantified in a 2-dimensional continuum, arithmetical reciprocals always are relevant. The Jews invent nothing; they inherit a spiritual domain "flowing with milk and honey" from thousands of years of Semitic musical experience. ${ }^{4}$ Both Greek and Jewish cultures know the same approximations to equal temperament, for which Plato demanded that the conception of number be broadened to include real number. Bible authors instead mythologize approximation with rational numbers adjusted to human need. Only at Heelan's highest level, $\mathrm{T}_{1}$, where temperament dogma competes with a regulative aesthetic activity involving other possible tunings, are contrary purposes reconciled. YHWH's refusal to let David build his temple can be understood as ensuring freedom of human choice; David accepts this rejection and contents himself with planning for one. When Solomon's temple eventually is dedicated the perfect unisons of David's 288 professional singers ("sons of Asaph") accompanied by 120 "priests with trumpets" raise such a "cloud of glory that the priests could not stand to minister." When New Jerusalem descends from the clouds at the end of Revelation these forces are dwarfed by a chorus of 144,000 male virgins "singing a new song" reserved for them, accompanied by 24 angelic harpists. These integers define pentatonic and heptatonic modal tuning systems which can be decoded by Heelan's algebra. There is no effort toward either musical or mathematical secrecy, nor any expectation that a reader can understand authorial models without the ability to "reckon" for himself. ${ }^{6}$ General meaning is always made evident by the narrative. Heelan's schema is a guide to a deeper esoteric allegory.

The perception of tonal beauty - and the very possibility of an aesthetic community - is dependent on a certain aural tolerance of approximation. There is no "crisis of the irrational" in Israel. What the Bible encodes for a musician is an awesome integration of opposites under the strict but elastic discipline of the ear.

\section{THE CYCLIC OCTAVE TO AS A PRIORI ASSUMPTION, AND A FIRST ENCOUNTER WITH LIMITS}

Both Greek and Jewish tuning theory assume a double octave as normative, framed by the proportion $1: 2:: 2: 4$ so that the first is "small" and the second "great." This idea is encoded in the three Hebrew consonants which spell Eden while summing to 124 as a numerical notation. In this arithmetical context it is useful to keep in mind Socrates' observation that " 2 is no more half than double," and an ancient affection for the notion of the universe as unfolding from the middle (Greek mese) as a kind of world egg. It proves convenient to the rigorous pursuit of perfect inverse symmetry to utilize our modern pitch class "D" - center of symmetry in alphabetical notation - as a fixed reference allowing Deity to think of himself simultaneously as "beginning, middle, and end," as illustrated in Figure 2.
Figure 2. The Model Octave on D as "Divinity"
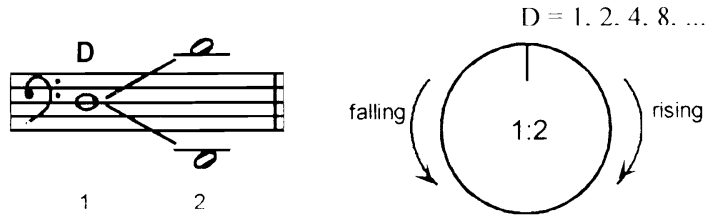

Physical application to string length (whether as multiples or as submultiples) has no effect on tonal "pitch class," which is regarded mathematically as an invariant "cyclic residue."

Multiple meanings abound, detested by Aristotelian philosophy but cherished by all ancient scribes in every language, with never enough symbols for the richness of their thought. We must imagine these "God numbers" in motion, self-moving restlessly for-evermore. ${ }^{7}$ But Judaism is breaking away from established Semitic practice: the highest deity in Mesopotamia is a "do-nothing," a "One" whose meaning is defined only by context, and Egyptian Osiris is clearly dead on first appearance. Bible authors conceive their only God as both the demiurgic unit from which all integers emanate as multiples, and as the comprehensive whole, encoded in the largest integer necessary, which affords judgment on its constituent submultiples. The Jewish deity is presented as a rather overstressed Good Shepherd within the midst of his people. The most adequate expression of this perspective on numerosity lies in the notion of factorials: it is articulated brilliantly during the first millennium AD in Sepher Yezirah where the "six working days of the creation week" are imagined as factorial six, meaning $1 \times 2 \times 3 \times 4 \times 5 \times 6=720$, and the contemplation of Deity on the Sabbath reserved for him involves factorial seven, $7 \times 720=5040$, which functions as Heelan's limit $\mathrm{L} \leq_{\mathrm{A}}$ in his third tuning $\left(\mathrm{T}_{7}\right)$. But Ezekiel already attests this limit perhaps a thousand years earlier as the seven years (meaning $2 \times 7 \times 360=5040$ "days and nights") when the fires in Jerusalem, the city of peace, are fed by burning all of the instruments of "Jewish warfare."

All of the biggest numerical limits in the Bible are examples of the deified number 4 defining the double octave. This phrase is Cyrus Gordon's translation of KiriathArba,${ }^{8}$ later Hebron, near where Sarah is buried in the cave of Machpelah after dying at 127 . Mother of the "first-born Jew" (Isaac, "He laughs"), her death age sums $1+2+4+$ $8+16+32+64$, the first seven powers of 2 from $2^{0}=1$ to $2^{6}$ needed for identifying him as a Jewish "new Horus" and applying ratio theory to heptatonic Davidic musicology." Here is where Isaac dies at 180, for 1:2::2:4 must be interpreted as 45:90::90:180 for the smallest 12-tribe musicology, while defining also the yearly half-cycle of the sun (and the geometer's semi-circle required for displaying Pythagorean triples). New Testament arithmetic needs a 13-digit integer which extends numerical doubling, meaning cyclic identity, to $2^{40}$, deliberately violating the principle of smallest integers to construct an ecumenical heaven large enough for the virtuous of all people.

Glancing ahead at Heelan's formulas we see that the prime numbers 3, 5, 7, and 11 define the four tuning systems he studied $\left(T_{3}, T_{5}, T_{7}, T_{11}\right)$ by their largest prime generators, but always within some appropriate limit $(\mathrm{L})$. His lattice is non-distributive in the sense that "the musical spaces of the different tunings cannot simply be represented by unions and intersections of Venn diagrams: a union of two musical spaces is more than the simple sum of the musical possibilities of each" for 
combinations of these primes create new intervals which none can produce by themselves. Furthermore, because the powers of prime numbers never agree except at the zero power equated with 1 , any rational formula produces an infinity of arithmetical possibilities while leaving the performer under the same constraints of self and instrument. No wonder the Jewish Deity discovers that "the imagination of man's heart is evil from his youth" (Gen. 9:21) for the womb of the cosmic octave 1:2 cannot be divided into aliquot parts by any rational numbers whatever. In this harmonical context "man" (as an odd integer) born of "woman" ("female" powers of 2 define the cyclic matrix) is indeed a sinful creature by nature, requiring an able algebraic "Shepherd" under any circumstances, and severe limitations on his behavior.

\section{TUNING $\mathrm{T}_{3}$ AS THE SPIRAL}

\section{OF MUSICAL FIFTHS AND FOURTHS, WITH L $=13$}

Heelan's tuning $\mathrm{T}_{3}$, rather unfairly known in the West as Pythagorean (which achieved the same results by a different process), is the historical serpentine spiral of alternating musical fifths and fourths displayed in Figure 3.

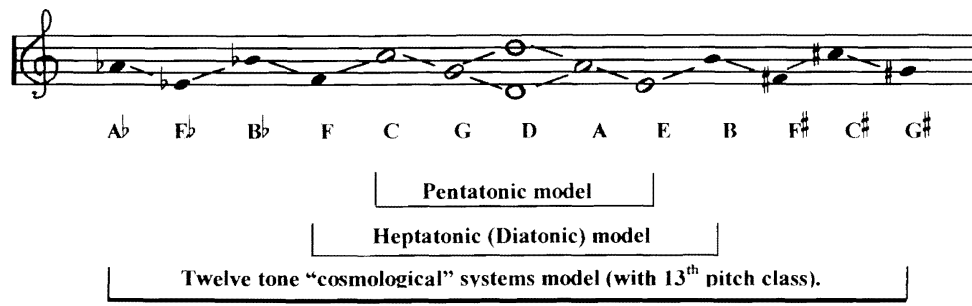

Figure 3. The "Great Serpent" Spiral Of Musical Fifths And Fourths

A near-coincidence in the pitch of the first and thirteenth tones limits practical application to 12 tones, and theoretical overview to 13. A bronze "serpent on a pole" is the only image YHWH ever authorized of his own "saving" power, and it was employed in the tribal cult until the reforms of Hezekiah c. $700 \mathrm{BC} .^{10}$

String-length ratios for this sequence are quantified easily by the ancient Chinese rule, not well-known in the West, "add or subtract one-third," i.e., to or from successive values for falling musical fourths of $3: 4$ or rising musical fifths of $3: 2$, reading from left to right. A less elegant rubric reading from right to left is subtract one-fourth for rising fourths of $3: 4$ or add one-half for falling fifths of $2: 3$. (Consecutive fourths of $3: 4$ where needed keep the tonal serpent within the frame of a single octave.) For modern vibration ratios (applied here when projecting scale order into tone-circles) the two rules are reversed. Because octave doubling has no effect on pitch class it can be eliminated for most purposes so that tones are identified merely as a sequence of triples, 1-39 , etc. emanating from unity and readily mapped by an abstract sequence of counters: - - e, etc. These are the "stones" from which God is able to "raise up children to Abraham."

In Figure 3, it is helpful to think of "D" as symbolizing Deity looking out on us from the middle of his world. Any set of consecutive triples (always the fewest possible, meaning one fewer than the number of pitch classes) can be mapped into any desired modal permutation order by doubling its value enough times to become the largest integer (i.e., "tallest" man, string, or pipe), and then doubling the others as needed to lie within an octave." To the right of Deity as "D" (i.e., to our left) add or subtract one-third produces vibration ratios for G C F .... His left arm (reading now from our left to right by the converse rule, subtract one-fourth or add one-half, holds vibration ratios for A E B ... On pitchpipes and harps this tuning order is visibly, aurally, and tangibly serpentine, as in Figure 4:

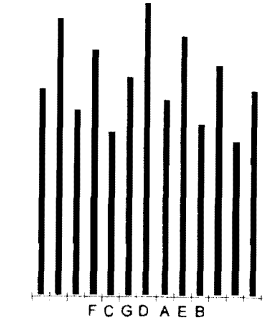

Figure 4. Spiral 5ths tuning

on harps and pitchpipes.

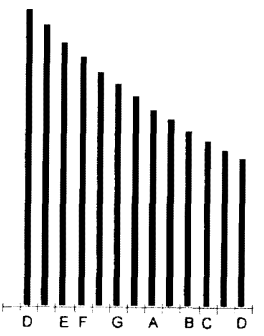

Figure 5. Scale order "straightens" the cosmic serpent.
The resulting scale order, however, is almost straight line as in Figure 5. Only in Equal Temperament can 12-tone scale order "straighten" the ancient Egyptian cosmic serpent Apophis perfectly. Caleb spies the Holy Land with Joshua with the same accuracy shown by Vincenzio Galileo in the sixteenth century AD when this temperament science had to be reinvented because its Mesopotamian origin was forgotten, Plato no longer was read with musical comprehension, Kabbalism had lost its Davidic clarity, and a new concept of zero as nothingness had intruded on the old idea of the "One" as the point of origin. ${ }^{12}$

\section{DAVIDIC AND NEW TESTAMENT VALIDATION OF TUNING T}

Three Hebrew consonants in David's name notate 4.6.4 to show perfect fifths of 2:3 and $3: 2$ in both directions from the center and correlating with $G: D:: D: A$ in the spiral tuning order of Figure 3. In the scale order of Figures 5 and 6 , however, these symmetric fifths overlap by a wholetone of $8: 9$, and the algebra transforms into the Greek musical proportion 12:9::8:6 (and 24:18:16:12 in the second or "great" octave) to define a triune Deity for tuning theory (encoding the fixed limits of conventional tetrachords in the normative modes).

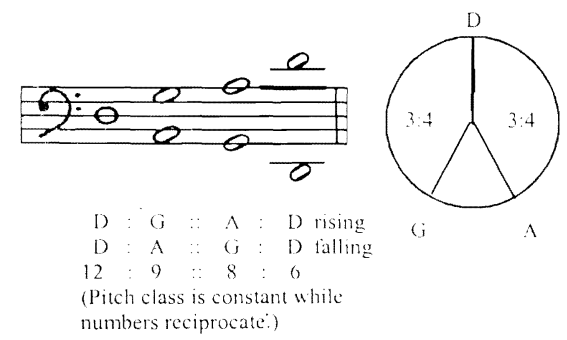

Figure 6. David as the "Musical Proportion" 12:9::8:6 
It is a personal fancy that $4+6+4=14$ probably shows David as an irrepressible teenager, obnoxious to his older brothers, and that the rays in his tone-circle show his metaphorical "slingshot" aimed at Goliath at six o'clock, and that his overlapping alternate meanings as " 8 "and " 9 " (i.e., reciprocal meanings of $2 / 3$ and $3 / 2$ ) illustrate both his personal duplicity and his dexterity in dodging Saul's spear, occasionally thrown at him from the throne at 12 o'clock. David's three tones are the only common elements in Heelan's four tunings. Isaac fathers twin sons Esau and Jacob at the age of 60 where these same ratios are encoded five times larger in $60: 45:: 40: 30$. When old and blind and deceived by his wife, Isaac confers the blessing due to first-born Esau on the trickster Jacob, for the smaller integer $(8$, or $5 \times 8=40)$ obviously is "born first." But it is indistinguishable in Semitic function (and to the blind Isaac's touch) from 9 and $5 \times 9=45$, the "younger son" required for Hebrew cosmology because 45 doubles naturally into 90,180 , and 360 which correlate music, geometry, and the calendar.

David's reorganization of Levite musicians into a professional band of 288 "prepared to cast lots for their duties, small and great, teacher and pupil alike"13 provides for a pentatonic (5-tone) scale displayed in Figure 7, and extending across a double octave.

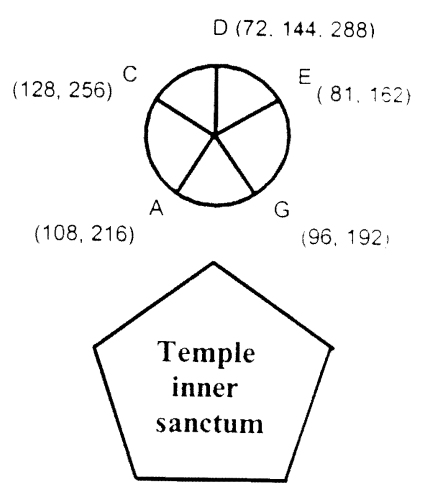

Figure 7. Egyptian Star Glyph As Pentatonic Scale

Any five consecutive pitch classes in tuning order require definition by 1-3-9-27-81; and perfect inverse symmetry in the scale requires doubling the middle value (9) until it is largest (i.e., through 18,36 , and 72 into 144 for the small octave, and again into 288 for a second or great octave). Other generators are doubled as required by the framing ratios 72:144::144:288 (in which Deity symbolized by D is "beginning, middle, and end"). In an octave circle mapping the radiance of the tone ratios the pattern suggests the star glyph in the Egyptian heavens: $\star$ And the rays outline the pentagonal doorway to the Davidic temple's Holy of Holies: (The inequality of pitch ratios tends to be glossed over in practice, for there are no semitones to vivify interval contrasts for voice and ear.)

Similar reasoning produces two more pitch classes for a self-symmetric heptatonic model known as "Mode of the Prophets" displayed in Figure 8.

The middle generator among 1-3-9-27-81-243-729 which define F C G D A E B is $3^{3}=27$, and it must be doubled through $54,108,216$, and 432 into 864 to embrace a small octave, and doubled again into 1,728 for a double octave. ${ }^{14}$ The radial pattern in Figure 8 should be rotated physically to enthrone each tone in turn at 12 o'clock; because the pattern is self-symmetric its numbers can be applied to the circle in the opposite direction. In this " $\mathrm{D}$ " mode the new pitch classes at $\mathrm{B}$ and $\mathrm{F}$, which introduce the first semitones, lie very close to a horizontal diameter and constitute an approximate kind of cosmic "balance"; their "tritone" ratio of 729:512 (F-G-A-B progresses through three wholetones of 8:9) approximates the square root of 2 with only a slight excess. (The balance and plumb line are primary Bible metaphors for personal behavior.) In all other modes the disposition of wholetones and semitones is asymmetric, for in all diatonic tunings they are locked into this pattern.

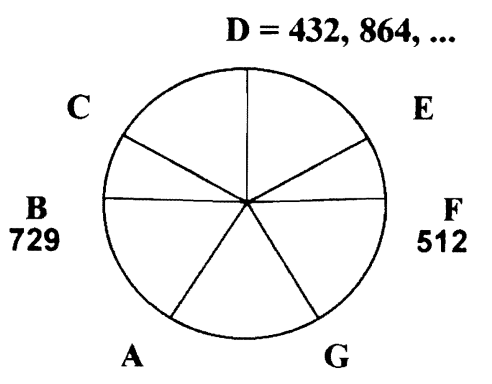

Figure 8. World Soul and Mode of the Prophets

In the $\mathrm{F}$ and $\mathrm{B}$ modes when either $2^{9}=512$ or $3^{6}=729$ is enthroned at $12 \mathrm{o}$ 'clock the other functions as plumb bob near six o'clock, as the square root of 2 approximation in each other's octaves. Don't fail to observe a slight oscillation in this plumb line by rotating Figure 8 both ways, for the reciprocal tritone ratios overlap by a useless microinterval known to musicians as a comma. The comma results from a trivial natural cyclic excess in the 2:3 ratios of the musical fifth, insignificant in Figures 5, 6, 7, and 8 , but an annoyance when allowed to accumulate. ${ }^{15}$

Abram explores this Holy Land of tonal cosmology while carrying a name whose letters sum to $3^{5}=243$, thus defining any six consecutive pitch classes in the spiral sequence. He is already as indifferent as David to "left and right" and so he embodies pitch classes D, G, C, F, B-flat, E-flat in one direction and D, A, E, B, F-sharp, C-sharp in the other in the way YHWH expects his Chosen to behave, indifferent to all reversals of fortune. These 11 pitch classes are the limit of perfect inverse symmetry in 12-tone approximations to equal temperament. At the age of 86, however, Abram, hoping for an heir, fathers Ishmael on Sarai's Egyptian maid Hagar. When 86 is read exponentially as $8^{6}=8 \times 8 \times 8 \times 8 \times 8 \times 8=262,144$ it embraces the first twelve tones in spiral fifths tuning $\left(3^{11}=177,147\right.$ is the largest male generator required). Later when informed by God (under the Hebrew name Elohim, whose letter values also sum to 86) that the aging Sarah will bear a legitimate heir at 90, Abram expresses regret: "Oh that Ishmael might live in thy sight!" And Elohim (86 read exponentially as $8^{6}$ ) assures him: "As for Ishmael, I have heard you; behold, I will bless him and make him fruitful and multiply him exceedingly; he shall be the father of twelve princes, and I will make him a great nation" (Gen 17:18-20). And so Abram becomes the patriarch also of 12 Arab tribes who remain proud of that descent. There can be little doubt that authors are reveling in the economy of an exponential notation, changing the names of both Deity and his leading characters in playing a game which only the numerate can follow. God power 
(as opposed to mankind's multiplicative power) is exponential, and is boldly advertised as such in New Testament Greek by using derivatives of the technical term dynamis.

\section{TUNING $\mathrm{T}_{5}$}

\section{AS “CHOSEN PEOPLE” AND SYMMETRIC ALTERNATIVE TO $\mathrm{T}_{3}$}

The ancient asymmetric Jewish "Mode of the Torah" (correlating with our "white key" mode on E) is defined across a double octave by the same 288 "singers" and 120 "priests with trumpets" who perform at the dedication of Solomon's temple. They are realigned now, however, in a "Just" tuning in which moveable sounds within Davidic tetrachords are generated by the prime number 5 as "pure" major thirds of $4: 5$ or complementary minor thirds of 5:6 within embracing fifths of 2:3. (Technically, the 2:3 ratio is now acquiring its own derivative arithmetical and harmonical means.) The Mode of the Torah in its canonic diatonic form is Plato's "true Hellenic mode" (Greek Dorian) correlating with our "white key" mode on E. ${ }^{16}$ Because of its asymmetry it requires a double octave framed by 120:60::60:30 in one direction and by $72: 144:: 144: 288$ in the other, as displayed in Table 1 for the "small" octave. (A paired "white key" mode on C, our normative major scale, needs the same numbers in the opposite direction.) David's three tones from $\mathrm{T}_{3}$ (i.e., the triune Deity) are common to all three modes.

\begin{tabular}{|c|l|l|l|l|l|l|l|l|}
\hline \multicolumn{7}{|c|}{$\begin{array}{c}\text { Table 1. The paired asymmetric modes on E and C, } \\
\text { transposed to D for direct correlation }\end{array}$} \\
\hline $\begin{array}{c}\text { "white key" E mode } \\
\text { transposed down }\end{array}$ & D & c & b & A & G & f & $\mathrm{e}^{b}$ & D \\
\hline $\begin{array}{c}\text { "white key" C mode } \\
\text { transposed up }\end{array}$ & D & e & f\# & G & A & b & c \# & D \\
\hline numbers increase & 72 & 80 & 90 & 96 & 108 & 120 & 135 & 144 \\
\hline numbers decrease & 60 & 54 & 48 & 45 & 40 & 36 & 32 & 30 \\
\hline
\end{tabular}

This paired system of $3+4+4=11$ tones thus provides 8 alternates for the 11 symmetries in Abram. Their model "small" octaves are integrated by factorial $6=720$ (the least common multiple of 60 and 144) at which point integers become available also for the pentatonic doorway to the temple (i.e., with alternate pitches for $\mathrm{c}$ and $\mathrm{C}$, and for $\mathrm{E}$ and e). Furthermore, $2^{9}=8 \times 8 \times 8=8^{3}=512$ now becomes available for an alternate square root of 2 ratio defining a-flat as a twelfth tone at 720:512 - which proves to be a "hair" (Ezekiel's metaphor) more accurate than 729:512 as a square root of 2 approximation, while coinciding almost perfectly with G-sharp. The two thirteen tone systems $\mathrm{T}_{3}$ and $\mathrm{T}_{5}$, considered aurally equivalent, are symmetric approximations to Equal Temperament, whose values lie within the commas between Spiral Fifths and Just tunings. Figure 9 displays the combined systems. ${ }^{17}$

Heelan's computation limit for both $\mathrm{L}_{\mathrm{p}}$ and $\mathrm{L}_{\mathrm{J}}$ is 12 pitch classes; both sets define $13^{\text {th }}$ under reciprocation; but the computation limit for a single octave is $\leq 8^{6}=262,144$ in $T_{3}$ and only $\leq$ factorial $6=720$ in $T_{5}$. A double octave Just tuning for the Chosen People is thus $2 \times 720=1,440$ which happens to be the sum of the letter values in Adam, who is properly claimed in Jewish folklore to contain the "seeds" of all tribal descendants. The tone-circle of Figure 9 shows the Jewish "sheepfold" in a way congenial for the eye; "David's slingshot" lies closest to Equal Temperament and suggests why God is sometimes flanked by two very superior "angels."

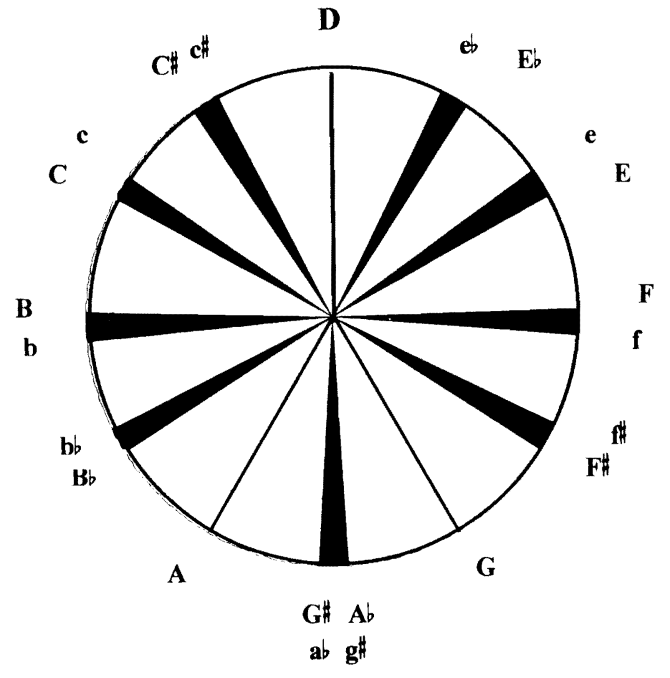

Figure 9. YHWH's "Sheepfold" for Tunings $T_{3}$ and $T_{5}$

The triune deity symbolized by G:D:A (structured by 12:9::8:6 encoded in David) "watches over" The triune deity symbolized by G:D:A (structured by 12:9::8:6 encoded in David) "watches over"
the commas between Spiral Fifths and Just tunings at other loci enclosing Equal temperament values. The excess in $\mathrm{T}_{3}$ is counterbalanced by the defect in $\mathrm{T}_{5}$ so that the two systems are in near perfect agreement again at $\mathrm{A} b \sim \mathrm{g} \sharp$ and $\mathrm{G} \sharp \sim \mathrm{a} b$. This natural serendipity was probably discovered by studying the symmetry systematically rather than by constructing it artificially. Thus the final result appears to be a "gift of the god numbers" deified in Mesopotamia.

\section{6. $\mathrm{T}_{7}$ PROVIDES DIVINE PERSPECTIVE}

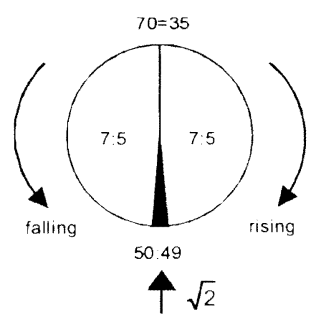

Figure 10. Septimal Comma 35:49::50:70

Heelan's tuning $T_{7}$ is named for Plato's friend Archytas who tried unwisely to integrate the first four primes into the normative Greek tetrachordal system. ${ }^{18}$ The prime number 7 deserves its exclusion from musical "working days" but serves two nobler functions: 1) as the cardinal number of our heptatonic musicology, still far from exhausted in its resources; and 2) in affording oversight into least noticeable differences. ${ }^{19}$ The simplest Diophantine approximation to the square root of 2 is the undersized ratio 7:5 displayed reciprocally in the proportion $35: 49:: 50: 70$. Most normal ears probably notice the difference between 49 and 50 under laboratory conditions, but their errors are halved by being centered symmetrically within the octave double $35: 70$; in this context 49 and 
50 are 99 percent correct and may inspire the popular notion of Deity's 99 names. The one percent error in each correlates with the Greek computation of the difference between a quartertone and a third tone (arithmetically 204/3-204/4=17 when computed in modern logarithmic cents, 1200 to the octave). This 49:50 septimal comma is displayed radially in Figure 10 to alert the eye to its 34 cent value. Its errors of 17 cents in each direction merit consideration as the extent of Divine Mercy in forgiving "sins of missing the mark." The Spiral Fifths comma at this point totals 24 cents overlap; the Just comma which emerges from 45:32 in this region has a defective comma of 20 cents, and both of these commas are centered (so that their errors are halved). Noah's "flood" (discussion is suppressed here) reduces these commas considerably but at the expense of a numerological deluge. Caleb's ratio reduces the error still further to the insignificance it has in Vincenzio Galilei's temperament of 1600 AD. But the one percent "tithe of a tithe" which Levites pass on to the High Priest covers the sins in the 49:50 ratio and probably justifies our accepting 7:5 as mapping Divine mercy. In this case the $50^{\text {th }}$ "small unit" symbolizes the Divine Son who takes the sins of the world upon Himself" in the manner exaggerated for the eye in Figure 11.

Figure 11. Analysis of the sins of approximation forgiven

within the septimal comma $35: 49:: 50: 70$. Satan's comma is greater than Isaac's.

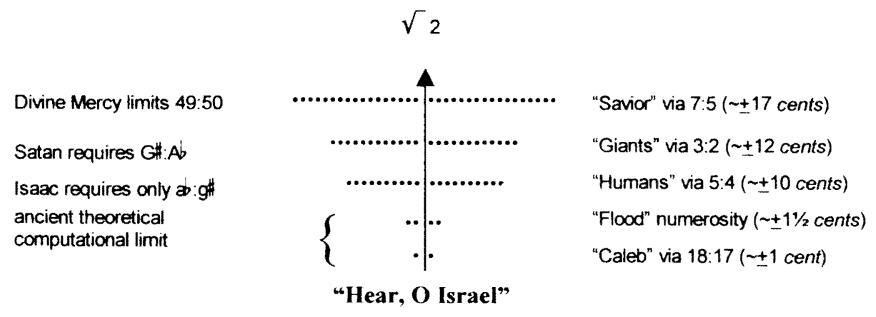

In the Old Testament, however, authors still think in terms of "God is my Savior" for they are unembarrassed to be using "One" to mean both whole and part. It is Isaiah and the Greeks who differentiate these functions.

Among the Chosen People defined by factorial $6=720$, the $7: 5$ square root computation is $7 / 5 \times 360=504$, but a reciprocal of $5 / 7 \times 720$ cannot be computed until the latter is multiplied by 7 into factorial $7=5040$. This gross inflation of numerosity serves no useful function (it defines an alternate $12^{\text {th }}$ tone we don't intend to use anyway) except in the niceties of theory. In Hindu and Platonic mythology the prime number 7 introduces a third and lower caste of characters whose fuller biblical functions have yet to be discovered (probably in the census data not yet decoded). "Satan" as a "fallen angel" of 729:512 from tuning $T_{3}$ loses out to a lower caste "fiver" of 720:512=45:32 in Tuning $T_{5}$ but in each case $512=8 \times 8 \times 8=2^{9}$ is surrogate for the "One" God Himself, and early Christian bishops recognized 888 as the sum of the numerical values in the Greek name of Jesus (IESOUS). But beyond this (in 7:5 displayed symmetrically within 5040) a third caste Savior has already "rescued" the whole system. (It is the smallest unit which "saves" the system.) The trivial excess in Spiral Fifths is offset symbolically, I suggest, by the ritual of male circumcision, and the defect in Just thirds is compensated by males feasting on a sacrificial lamb once a year at the temple. The "son of a priest" who composed Revelation understood perfectly that "Satan" (meaning $3^{6}=729$, encoded in 666) had to be allowed his period on the throne of heaven for the resurrection drama to be completed by 888 , meaning by $8^{3}=512$ in the region of 6 o'clock. Tuning $\mathrm{T}_{7}$ has a computational limit of 5040 within which Plato found 37 candidates for "guardians" of his model city in Laws. David's authors actually name 37 warriors when telling of the fighting prowess of his private band of "thirty."

\section{HOW TUNING $\mathrm{T}_{11}$ EMPHASIZES THE UNCERTAINTY PRINCIPLE}

Heelan's fourth tuning, $T_{11}$ named for the astronomer Ptolemy who writes in the middle of the second century AD, is not Platonic except metaphorically. Ptolemy is justly proud of the economy of his system: four numbers 9-10-11-12 framed by a familiar perfect fourth of $3: 4$ (belonging also to the three older tunings) illustrate how a tetrachord can be made "barbaric" for the ear by subdividing it into three gradually diminishing intervals which cannot be discriminated successfully from each other in any normative musical way. (Differences between successive intervals of 182, 165, and 150 cents are less than the commas between $T_{3}$ and $T_{5}$.) But if this is true for primes like 11 it is also true for all larger primes; if God forgives any errors whatever in the computation of equal temperament boundary markers then the door is wide open for ambiguity as the products of other primes drift cyclically within the commas forgiven. ${ }^{20}$ And this appears to be how Jewish authors view their allegory. In this system any man however humble (meaning any odd integer), is a potential "priest" in some context. Because any tone among the 12 can be the tonic of a tuning system $T_{1}$, and pitch is not fixed in any case, the septimal comma of Divine Forgiveness can be located anywhere. Figure 12 attempts to convey, by its twelve colored septimal commas of 49:50, the amount of human freedom guaranteed within the octave by the "self-limitation" of a merciful Deity which YHWH becomes.

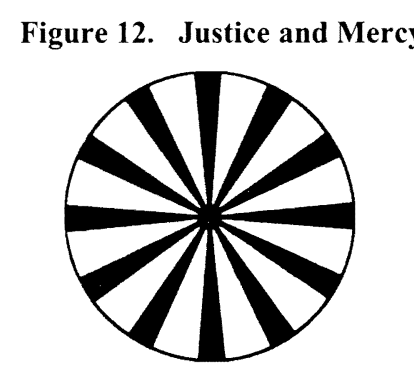

Within the "Jubilee commas" graphed as colored segments surrounding Equal Temperamen values the ear cannot discriminate other pitch classes in a musical context. This small amount of merciful insensitivity is a common assumption of Greek and Davidic musicology, making musical collaboration possible but inviting alternative conceptions.

Greek authors emphasize human limitation; Jewish authors emphasize Divine Mercy These opposing conceptions are in perfect agreement arithmetically when studied musically - which philology has not yet learned to do. Biblical conceptions of God and Man are adjusted perfectly to each other.

\section{THE NAMES OF GOD}

So great has been Jewish respect for the Torah (the Pentateuch) that it was assumed only Moses could have written it, and this is not far wrong. The Hebrew letters in Moses sum to 345 and compare favorably with Plato's algebra for the same $T_{5}$ tuning 
as " $4: 3$ mated with the 5." But the El Shaddai whom Abraham knew also sums to 345 , and $3 \times 4 \times 5=60$ defines the basic octave of the system as $2: 1=60: 30$

The YHWH who assures Moses that Abram/Abraham had known him as $\mathrm{El}$ Shaddai encodes 10.5.6.5, a formula which possesses an awesome range of allusions to both Babylonian and Bible harmonical allegory, of sufficient complexity to produce a Davidic 12-tone temperament. ${ }^{21}$ The numbers 10.5 .6 .5 sum to 26 , and 26 is the significant "tail" in the biblical cube root value of 126 meaning 1.26. But $10+5$ which sums to 15 is the number once deified by Ishtar, the great mother Goddess whose "powers" YHWH usurps, and whose doubling produces 30 and 60 and their multiples. $10 \times 5=50$ symbolizes Enlil, the active head of the Mesopotamian pantheon, and $6 \times 5=30$ symbolizes the Moon god Sin. 10x6=60 symbolizes Anu/An, the "do-nothing" head of the pantheon, and 60 was written as a large "1" anticipating monotheism - where unity is burdened with cares. But in Babylonian base 60 this " 1 " had to be interpreted as $60^{5}$ to incorporate Abram symmetry (the worth of 60 is determined by the place value of the largest base 60 fraction associated with it, in this case defining the $12^{\text {th }}$ tone). But when $60^{5}$ is interpreted as $\mathrm{YHWH}$ and read exponentially in base 10 it becomes $10^{5} \times 6^{5}=605=777,600,000-$ a grotesque expansion of the 600,000 really needed in base 10. A scribal "translation jest" is involved with the Jewish Godhead, unknown to later "unmusical" generations. And in this jest we meet Noah's "father" who dies at 777 just five years before the flood, and Noah at 600 followed by three "sons" as 000 - meaning derivative fivers $(5,25$, and 125 before they have been doubled to "fill out" their places). Fortunately for our understanding, Plutarch (initiated as a priest of Isis) notices the same thing happening at Delphi, assures us that in Egypt "60 is the first of numbers," that Egyptian further subdivisions are by 60 s, and coyly alludes to the mysterious Greek letter E meaning " 5 " engraved on a stone at the sacred shrine. ${ }^{22}$ Both the Greek Apollo and the Jewish YHWH deify $60^{5}$ (written in cuneiform as "1") as meaning 777,600,000, making both God and man "fivers" (but in quite different senses) in both cultures. Today we need Greeks like Plato and Plutarch to help us learn again how to read Jewish scripture with Philo's understanding. My respect for Heelan's algebra lies in its promise to provide a new Bible hermeneutics by alerting modern scholars to the mental adjustments they must make when trying to rediscover the authorial logic in numerological references.

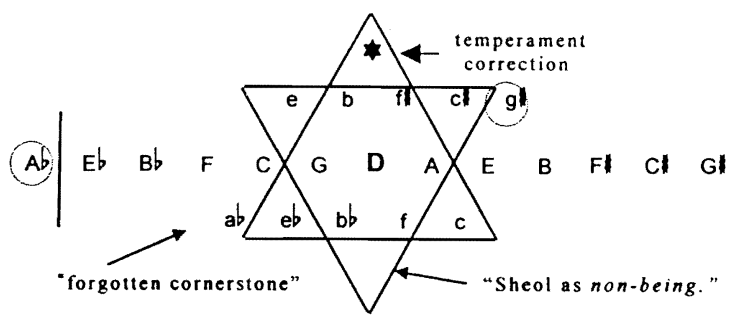

Figure 13

The Chosen People as 13 alternates in systems T3 and T5, sharing G, D, A in common. (The "Davidic" cube root temperament correction of $1 / 125$ is available only in the upright triangle which maps "male" reciprocals.)

For instance, Jews are taught to say Adonai when they see יהןה (YHWH) (considered too sacred to pronounce except once a year by the High Priest in the solitude of the inner sanctum), and the Hebrew in Adonai sums to 86 which, as $8^{6}$, also en- codes the same12 tones in spiral fifths as YHWH (and also allowing the thirteenth to appear only as a reciprocal). The Hebrew letters in El-Olam, translated as "Everlasting God," notate 30 and 40 which frame tetrachords of 3:4 in Spiral Fifths, and they sum to 70 which holds the "saving" formula of $35: 49:: 50: 70$. This formula justifies the fifty year sacred calendar (50:70 is a repetition of 35:49) within which nothing can be harvested in any $7^{\text {th }}$ year ( 7 is not a "working" number) nor in any $50^{\text {th }}$ (there are no products of $2,3,5$, or 7 between $49 \times 360=17,640$ and $50 \times 360=18,000$ (the circumference in cubits of Ezekiel's temple area). These examples of Hebrew and Greek gematria, beloved by Kabbalists, hold some of the most powerful algebra in the Bible.

Figure 13 shows the Chosen as "the fewest of all people" in two different systems. In Revelation the city of New Jerusalem descends from the clouds as the cube of 12,000 - meaning 1,728,000,000,000. Its "head" digits of 1,728 encode the double octave of Plato's World Soul (see Table 2). Its tail of nine trailing zeros are exactly sufficient to complete the spiral of 13 tones in spiral fifths, supremely confident that all "sins" are atoned. . $^{23}$

Table 2. New Jerusalem

"First and "last" disagree by a comma but are assumed to coincide, as treated in musical practice

\begin{tabular}{|c|r|r|r|r|}
\hline tone & \multicolumn{1}{|c|}{ number } & read down & read up \\
\hline F & $1,024,000,000,000$ & $\times 3 / 2=$ & \\
\hline C & $1,536,000,000,000$ & $\times 3 / 4=$ & $\times 2 / 3=$ \\
\hline G & $1,152,000,000,000$ & $\times 3 / 4=$ & $\times 4 / 3=$ \\
\hline D & $1,728,000,000,000$ & $\times 3 / 2=$ & $\times 2 / 3=$ \\
A & $1,296,000,000,000$ & $\times 3 / 4=$ & $\times 4 / 3=$ \\
\hline E & $972,000,000,000$ & $\times 3 / 4=$ & $\times 4 / 3=$ \\
\hline B & $1,458,000,000,000$ & $\times 3 / 2=$ & $\times 2 / 3=$ \\
\hline F\# & $1,093,500,000,000$ & $\times 3 / 4=$ & $\times 4 / 3=$ \\
\hline C\# & $1,640,250,000,000$ & $\times 3 / 2=$ & $\times 2 / 3=$ \\
\hline G\# & $1,230,187,500,000$ & $\times 3 / 4=$ & $\times 4 / 3=$ \\
D\# & $922,640,625,000$ & $\times 3 / 4=$ & $\times 4 / 3=$ \\
\hline A\# & $1,383,960,937,500$ & $\times 3 / 2=$ & $\times 2 / 3=$ \\
\hline E\# & $1,037,970,703,125$ & & $\times 4 / 3=$ \\
\hline
\end{tabular}

\section{CONCLUSIONS}

Bible mythography is a mode of thinking we treat as pre-scientific; Heelan's algebra suggests how it might be considered as prescient. In its fullest development Judaic thought seems a perfect union of the knowledge and wisdom of its own age and, for musicians, possibly a religion for all time, graciously attuned to human ears. What more could our age expect of any theology, ancient or modern? The Deity enthroned here to exercise aesthetic judgment allows music to be an art of the universal within the particular, forever in contrast to philosophy as the art of the disembodied universal. Heelan as a priestly philosopher is forging a new tool which promises to facilitate ecumenical understanding, and to promote the healing of old animosities, and not by altering anybody's text, but by enlarging everybody's imagination. ${ }^{24}$

Emeritus, Brooklyn College 


\section{NOTES}

Patrick A. Heelan, "Music as Basic Metaphor and Deep Structure in Plato and in Ancient Cultures," Journal of Social and Biological Structures, v. 2, no. 4 (1979): 279-291.

2 See Ernest G.McClain, The Pythagorean Plato: Prelude to the Song Itself (York Beach,MN: Nicolas-Hays, 1978, 1984), for my analysis of Plato's mathematical allegories - developed before I understood their relation to the Bible.

${ }_{3}^{3}$ Asserted to Moses, Deut. 7:7. All quotations are from the Revised Standard Version, (Nelson and Sons, 1952) unless otherwise noted.

Reiterated 24 times in the Old Testament, and expanded at Deut 6:10-11 to include: "great and goodly cities, which you did not build, and houses full of all good things, which you did not fill, and cisterns hewn out, which you did not hew, and vineyards and olive trees, which you did not plant."

5 II Chron. 5:11-13.

6 Revelation 13:18.

7 This doctrine of self-moving numbers, indubitably authentic in Pythagorean thought, ensures lasting ridicule for Aristotles' classmate Xenocrates.

${ }^{8}$ See also the reference in Anchor Bible Dictionary.

These fractions were notated in the hieroglyph for the eye of the hawk symbolizing the newborn Pharaoh, an idea transformed into the notion of YHWH as a "great eagle" watching over Israel. They are the foundation of ratio theory as it was studied in the pattern of ten pebbles in the Holy Tetractys.

"Make a fiery serpent, and set it on a pole; and everyone who is bitten, when he sees it, shall live" (Numbers 21:8).

"Israel's first king, Saul, selected by Samuel with divine assistance, is a "head" taller than anyone else.

12 As a place marker, zero may carry the implication that "this place is full," not empty.

13 As a place mark

14 The "small" digits for "New Jerusalem" in Revelation.

See Songs from Silence by Kilmer, Crocker, and Brown (Bit Enki records, 1975) for an excellent discussion of Assyrian lyre tuning texts from ca. $1400 \mathrm{BC}$ which explains in careful detail how all seven modes are tuned in both directions, anticipating Greek tuning theory by nearly a thousand years.

16 Jewish modes are identified by A. Z. Idelsohn in Jewish Music in its Historical Development (Schocken, 1967), but various traditional ornaments and pitch inflections may vary widely from the Greek norms displayed here.

17 Commas of 80:81 between the two systems are the difference between a wholetone of 9:8 and one of 10:9.

The Archytas tuning is generally assumed to have been only theoretical, and never adopted.

19 On extremely resonant stringed instruments like the piano the seventh partial sounds this 7:5 interval (often very powerfully on Steinway pianos), but the performer who is nearest and thus in the best location to hear them normally has attention focused elsewhere, and other auditors are unlikely to be near enough to perceive them.

Several larger primes enter Greek tuning theory "by the back door" when other intervals are simply halved numerically. Thus 9:8 when halved produces the tempered semitone 18:17 of Caleb and Galilei, and 10:9 produces 20:19, and 15:16 produces the two quartentones 30:31 and 31:32. But these larger prines are (5) not generally computed, although Adam's death at 930 occurs precisely where the Greek Just enharmonic genera is reciprocated. This matter requires further study. Numerical subtleties prove endless.

See my essay, "The 'Star of David' as Jewish Harmonical Metaphor," International Journal of Musicology, 6 (1997): 25-49.

${ }^{22}$ See his essays "Isis and Osiris" and "The E at Delphi" in volume 5 of his Moralia (Harvard, 1936).

23 The last few tones are named differently than in Figure 3 only because I always interpret the largest ${ }_{24}$ number (as "king") as enthroned on D for my own sanity.

My understanding of Bible musicology is owed mainly to a continuing dialogue, now in its fifth decade, with Siegmund Levarie, who inspired much of this analysis and contributed consistently to it. We are both unwilling to pursue gematria beyond our own understanding of Bible musicology, won directly from its arithmetical clues. The arithmetic presented here owes nothing to Kabbalism except a shared faith in symbolic
meaning and a certain prodding to look more deeply into Hebrew than we are able. Kabbalistic fancy must meaning and a certain prodding to look more deeply into Hebrew than we are able. Kabbalistic fancy must
not be allowed to obscure the very real science in Davidic musicology. This study needs more not be allowed to obscure the very real science in Davidic musicology. This study needs more
interdisciplinary collaboration by a new generation freed from old prejudices. Harvey Wheeler awakened interdisciplinary collaboration by a new generation freed from old prejudices. Harvey Wheeler awakened
my interest in political science models. Richard Sacksteder ensured a degree of mathematical rigor. A period of intense collaboration with Antonio de Nicolás in studying Rigvedic symbolism alerted me to simila harmonical models in the Bible. Twenty years of discussing Plato with the incomparable Greek scholar John Bremer proves invaluable. These friends and certain others are responsible for my results in more ways than can be acknowledged here. The Myth of Invariance: The Origins of the Gods, Mathematics and Music From the RG VEDA to Plato (New York: Nicolas Hays, 1976) is my earliest survey of pre-biblical mythology, with an introduction by Siegmund Levarie and edited by Patrick A. Heelan. 